\title{
A Case Report of False Positive FDG- PET/CT Mediastinal Lymph Node in Oesophageal Adenocarcinoma Revealed to be an Anthracotic and Anthracosilicotic Spindle Cell Pseudotumor (AASCP)
}

\author{
Haidar $\mathbf{M}^{1}$, Bannoura $\mathbf{S}^{2}$, Hallal $\mathbf{A}^{3^{*}}$, Ghanem AA ${ }^{1}$, Dergham $\mathbf{M Y}^{1}$, Barakat $\mathrm{A}^{1}$, Jreige $\mathbf{M}^{2}$ and Shabb $\mathbf{N}^{2}$ \\ ${ }^{1}$ Department of Diagnostic Radiology department, American University of Beirut Medical Center, Beirut, Lebanon \\ ${ }^{2}$ Department of Pathology, American University of Beirut Medical Center, Beirut, Lebanon \\ ${ }^{3}$ Department of Surgery, American University of Beirut Medical Center, Beirut, Lebanon \\ ${ }^{4}$ Department of Nuclear Medicine, Centre Hospitalier Universitaire Vaudois, Beirut, Lebanon
}

*Corresponding author: Ali Hallal, Surgery department, American University of Beirut Medical Center, Beirut, Lebanon, Tel: 9611350000; E-mail: ah05@aub.edu.lb

Received date: June 07, 2017; Accepted date: July 10, 2017; Published date: July 17, 2017

Copyright: (c) 2017 Haidar M, et al. This is an openaccess article distributed under the terms of the Creative Commons Attribution License, which permits unrestricted use, distribution, and reproduction in any medium, provided the original author and source are credited.

\begin{abstract}
Anthracotic and anthracosilicotic spindle cell proliferation (AASCP) is a rare reactive proliferative entity of phagocytic histiocytes which can affect hilar and mediastinal lymph nodes. Fluorodeoxyglucose-positron emission tomography (FDG-PET) has been used for the clinical diagnosis and staging of oesophageal adenocarcinoma. We report the first case of AASCP exhibiting false positivity on FDG-PET imaging.

A 76-year-old man with distal esophageal adenocarcinoma underwent PET/CT for staging revealing a positive mediastinal lymph node involvement. The patient underwent Endobronchial Ultrasound Fine Needle Aspiration Biopsy (EBUS-FNA) followed by an oesophagectomy with lymph node dissection. The histological diagnosis of the mediastinal lymphadenopathy was AASCP. In mediastinal lymph nodes of esophageal adenocarcinoma, AASCP could be a cause of false-positivity on FDG-PET imaging.
\end{abstract}

Keywords: Anthracotic and anthracosilicotic spindle cell pseudotumor; Esophageal adenocarcinoma; Fluorodeoxyglucose positron emission tomography; PET/CT

\section{Introduction}

Anthracotic and Anthracosilicotic Spindle Cell Pseudotumor (AASCP) is a reactive proliferative lesion rarely encountered in mediastinal lymphadenopathy and characterized by phenotypic transformation of histiocytes into numerous spindle cells due to the foreign dust silica [1]. Anthracosis, also known as coal workers' pneumoconiosis, is seen in coal workers and is caused by inhalation and deposition of black pigments of carbon Air pollution, biomass smoke, and cigarette smoke can similarly lead to environmental anthracosis [2]. Both silicosis and anthracosis have been reported due to nonoccupational causes [3]. Symptoms are non-specific and mostly overlap with other causes of restrictive lung disease, frequently culminating in progressive massive fibrosis [4].

AASCP with mediastinal lymph node involvement can mimic neoplasia and has a broad differential diagnosis including infection diseases (tuberculosis, coccidioidomycosis, and histoplasmosis), granulomatous disease (mainly sarcoidosis), malignancies (mainly lung cancer, Hodgkin's and non-Hodgkin's lymphoma) and other conditions such as berylliosis [5]. This benign lesion has been eveneven been reported to mimic the rare occurrence of supradiaphragmatic lymph node metastasis from a primary prostate cancer [6].

Herein, we report a case of 76-year-old male referred for staging of an esophageal adenocarcinoma with a right lower paratracheal lymph node, showed to be active of on FDG PET/CT, and revealed to be on the post-surgical anatomo-pathologic examination, an AASCP.

\section{Case Report}

We report the case of a 76-year-old male who on investigation for iron deficiency anemia was found to have a distal esophageal adenocarcinoma measuring $2 \mathrm{~cm}$ in size and is located at $35 \mathrm{~cm}$ from the incisors (Figure 1). His medical history is otherwise positive for type 2 Diabetes Mellitus with a controlled blood sugar and HbAlc level. Social history was significant for living in the Northern Lebanese area of Akkar, which is close to areas of industrial growth and air pollution.

Endoscopic Ultrasound (EUS) showed the tumor to be invading the muscularis propria with negative lymph node T2N0 (Clinical Stage 1B). Computed Tomography of the chest and abdomen showed a left 7 th rib sclerotic lesion suggestive of metastasis. As a result, a PET/CT whole body with F18-Flurorodeoxyglucose (FDG) scan was performed. The PET/CT scan showed wall thickening and increased activity within the distal esophagus at the site of the known esophageal tumor and an unexpected $1 \mathrm{~cm}$ right lower paratracheal (4R) lymph node showing increased radiotracer uptake with a Standardized Uptake Value SUV-max of 4.53 (Figure 2).

Considering the PET/CT results as a positive nodal invasion, the patient wasupstaged to a T2N1 Stage IIB, requiring as a result neoadjuvant treatment. The question whether this is a metastatic node was entertained in our multidisciplinary tumor board meeting and an Endobronchial Ultrasound Biopsy Fine Needle aspiration (EBUS- 
Citation: Haidar M, Bannoura S, Hallal A, Ghanem AA, Dergham MY, et al. (2017) A Case Report of False Positive FDG- PET/CT Mediastinal Lymph Node in Oesophageal Adenocarcinoma Revealed to be an Anthracotic and Anthracosilicotic Spindle Cell Pseudotumor (AASCP). J Nucl Med Radiat Ther 8: 335. doi:10.4172/2155-9619.1000335

Page 2 of 4

FNA) was recommended and performed and turned out to be negative.

The patient proceeded to surgery directly and an Ivor Lewis Esophagectomy was performed successfully. The final histopathology staged the disease as T1N0M0 moderately differentiated adenocarcinoma (Grade 2) of the esophagus Stage 1A. The questionable $4 \mathrm{R}$ lymph node turned out to be an AASCP.

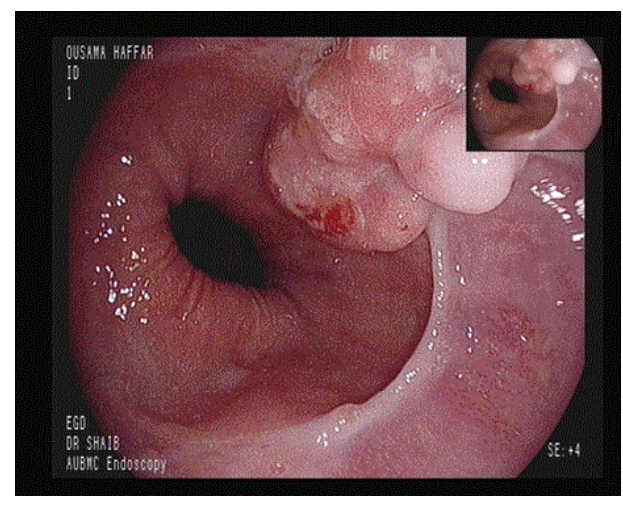

Figure 1: Distal esophageal tumor measuring $2 \mathrm{~cm}$ in size and located at $35 \mathrm{~cm}$ from the incisors.

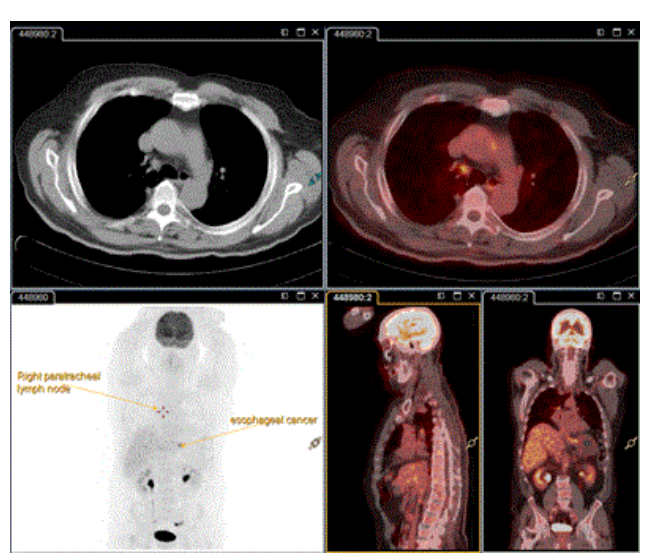

Figure 2: Man with FDG avid lower esophageal cancer and active right paratracheal lymph node (SUVmax=4.53). No evidence of distant metastasis.

The received "level $4 \mathrm{R}$ " mediastinal lymph node measured $1.5 \times 1.3$ $\times 1.1 \mathrm{~cm}$ and had a slightly firm consistency. The cut surface was smooth, tan black and homogenous. Microscopically, on low power view, the lymph node was partially involved by a proliferative lesion in a vague storiform pattern. On high magnification the lesion was composed of bland spindle cells many of which contained variable amounts of anthracotic pigment and interspersed dense collagen deposition.

The other submitted " $4 \mathrm{R}$ " lymph nodes were also anthracotic. The patient underwent a transbronchial FNA prior to operative resection which was adequate for analysis and negative for adenocarcinoma. It was composed of mature small lymphocytes, normal bronchial epithelium and numerous anthracotic pigment-containing cells either spindle or polygonal with an abundant background anthracotic pigment (Figure 3).

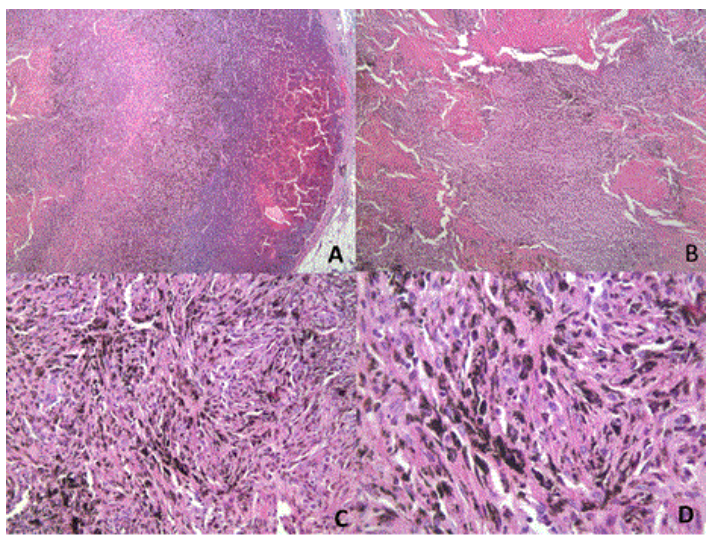

Figure 3: (A) AASCP. H and E stain. Low power view (40X) shows the proliferative process partially involving the lymph node. (B) Prominent fibrosis. (C and D) The spindle nature of the cells along with the prominent anthracosis (100X, 400X).

Immunohistochemically the lesional cells were diffusely positive for CD68, SMA, MSA and Vimentin, focally positive Caldesmin and negative for ALK, CD34, CD21, Cyclin D1, Calponin, Desmin, S100 and Melan A. The proliferative index (Ki-67) was approximately $10 \%$. Special stains were performed on the submitted tissue; Masson trichrome highlighted the dense collagen fibers. Both melanin and iron stains were negative. Examination of tissue sections with a polarizer light was negative (Figure 4).

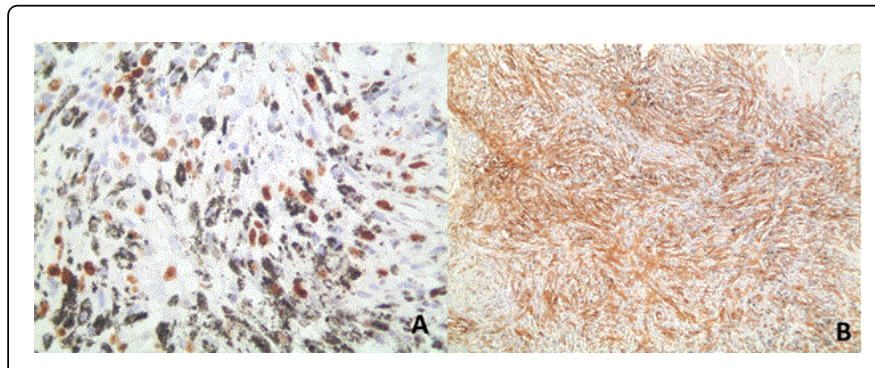

Figure 4: (A) Immunohistochemistry staining. Proliferative index (Ki67). (B) Smooth muscle actin (SMA).

Based on the above findings a diagnosis of "anthracotic and anthracosilicotic spindle-cell pseudotumor" was made. This is a rare reactive process that results in significant fibrosis and collagen deposition and in which there is conversion of macrophages into numerous spindle cells mimicking neoplastic processes. It can occur in the absence of established lung silicosis and may show histologically an infiltrative and destructive growth with extracapsular and destructive spread mimicking sarcoma [7].

The differential diagnosis in this case included; follicular dendritic cell tumor (FDCT), Mycobacterial spindle-cell tumor, Spindle cell melanoma, Kaposi's sarcoma and Intranodal hemorrhagic spindle cell tumor with amianthoid fibers (Palisaded myofibroblastoma), and inflammatory myofibroblastic tumor. 
The other diagnostic possibilities were excluded as follows: Negative CD21 ruled out Follicular dendritic cell tumor. Spindle cell melanoma was ruled out by bland cytology of the spindle cells and negative S100 and Melan A stain. Intranodal hemorrhagic spindle cell tumor (Palisaded myofibroblastoma) was excluded due to its occurrence mainly in the groin region and the absence of the characteristic amianthoid fibers. Mycobacterial spindle cell tumor and Kaposi sarcoma have histologic features that differ slightly from those in our case. Additionally both entities occur in immunocompromised and or AIDS patients. Our patient hoverer however is immune-competent making these diagnoses untenable.

\section{Discussion}

Adenocarcinoma of the esophagus is a malignant epithelial tumor of the esophagus with glandular differentiation arising predominantly from Barrett mucosa in the lower third of the esophagus. At the time of diagnosis, most tumors are advanced with deep infiltration of the esophageal wall [8]. Adenocarcinomas spread first locally and infiltrate the oesophageal wall with a possible extension through the esophageal wall into adventitial tissue, and then into adjacent organs or tissues are similar to squamous cell carcinoma. Barrett associated adenocarcinoma metastasizes to para-esophageal and paracardial lymph nodes, those of the lesser curvature of the stomach and the celiac nodes.

The major prognostic factors in adenocarcinoma of the esophagus are the depth of mural invasion and the presence or absence of lymph node or distant metastasis. Conventional staging methods include upper endoscopic gastroduodenoscopy, endoscopic ultrasonography (US), and computed tomography (CT) of the thorax and abdomen. The routine use of integrated positron emission tomography (PET)/CT with 18-fluoro-2-deoxy-d-glucose (FDG) in evaluation of patients with esophageal carcinoma is increasing, it has been reported to be useful in initial staging, follow-up and assessment of therapeutic response, and detection of recurrent malignancy $[9,10]$.

Locoregional lymph nodes in esophageal cancer depend to some extent on the location of the primary tumor in the esophagus and are normally resected with the primary tumor at the time of esophagectomy [11]. Limitation of PET/CT in the evaluation of nodal metastasis was mainly due to the FDG uptake within periesophageal lymph nodes that are anatomically close to the primary tumor which is difficult to differentiate from uptake within the esophagus itself. This is mainly due to the limited spatial resolution of PET [12]. In addition, PET can result in false negative outcome in cases of microscopic metastatic disease within lymph nodes that may not demonstrate sufficient FDG uptake for detection [13]. Furthermore, FDG uptake within lymph nodes can occur in benign disease such as granulomatous infection (secondary to histoplasmosis or tuberculosis) or Sarcoidosis.

This entertains the importance of taking a detailed exposure or occupational history from patients presenting with mediastinal lymphadenopathy, which was missednot clearly investigated for in our initial investigationsinitally. In a metanalysis done by van Westreenen et al. PET/CT had a sensitivity of $51 \%$ and specificity of $84 \%$ for detection of nodal metastases in preoperative staging setting in patient diagnosed with esophageal cancer [14].

No association between adenocarcinoma of the esophagus and AASCP has been reported to date in the literature.
Endoscopic US is superior to PET/CT in detection of locoregional nodal metastases and has the added advantage over PET/CT of allowing biopsy of suspicious lymph nodes at the time of detection [15]. However PET/CT is still considered as a reliable modality in the initial staging and for assessment of treatment response especially in the evaluation of distant metastasis [16]. PET/CT is shown in a recent study to provide incremental staging information, changing management in one third of patients [17].

\section{Conclusion}

Although being a rare finding, AASCP which is a benign condition should be considered in the differential diagnosis of nodal involvement in esophageal cancer on PET/CT imaging. PET/CT is still considered as an interesting method in the initial staging and for -assessment of treatment response especially in the evaluation of distant metastasis. However it has a limited role in the evaluation of locoregional nodal involvement in esophageal cancer and its results should be interpreted in conjunction of with endoscopic US and pathologic data.

\section{References}

1. Mossman BT, Churg A (1998) Mechanisms in the pathogenesis of asbestosis and silicosis. Am J RespirCrit Care Med 157: 1666-1680.

2. Comert SS, Dogan C, Caglayan B (2012) The demographic, clinical, radiographic and bronchoscopic evaluation of anthracosis and anthracofibrosis cases. J Pulmonar Respir Med 2: 119.

3. Spalgais S (2015) Nonoccupational anthracofibrosis/anthracosilicosis from Ladakh in Jammu and Kashmir, India: A case series. Indian J Occup Environ Med 19: 159-166.

4. Petsonk E, Rose C, Cohen R (2013) Coal mine dust lung disease. New lessons from old exposure. Am J Respir Crit Care Med 187: 1178-1185.

5. Travis DW, Colby TV, Koss MN (2002) Non-neoplastic disorders of the lower respiratory tract. Chest 1176-1177.

6. Pinaquy JB (2015) Anthracosis mimicking mediastinal lymph node metastases with $18 \mathrm{f}$-fcholine in high-risk prostate cancer. Clin Nuclear Med 40: e253-e254.

7. Argani P, Ghossein R, Rosai J (1998) Anthracotic and anthracosilicotic spindle cell pseudotumors of mediastinal lymph nodes: Report of five cases of a reactive lesion that simulates malignancy. Hum Pathol 29: 851-855.

8. Flanagan FL, Dehdashti F, Siegel BA (1997) Staging of esophageal cancer with 18F-fluorodeoxyglucose positron emission tomography. AJR Am J Roentgenol 168: 417-424.

9. Liberale G, Van Laethem JL, Gay F (2004) The role of PET scan in the preoperative management of oesophageal cancer. Eur J SurgOncol 30: 942-947.

10. Westerterp M, van Westreenen HL, Reitsma JB (2005) Esophageal cancer: CT, endoscopic US, and FDG PET for assessment of response to neoadjuvant therapy-systematic review. Radiol 236: 841-851.

11. Greene F, Fritz A, Balch C (2002) AJCC cancer staging handbook part III Digestive system 9-esophagus.

12. Rice TW (2000) Clinical staging of esophageal carcinoma: CT, EUS and PET. Chest Surg Clin N Am 10: 471-485.

13. Lerut T, Flamen P, Ectors N (2000) Histopathologic validation of lymph node staging with FDGPET scan in cancer of the esophagus and gastroesophageal junction: A prospective study based on primary surgery with extensive lymphadenectomy. Ann Surg 232: 743-752.

14. Van Westreenen HL, Westerterp M, Bossuyt PM (2004) Systematic review of the staging performance of $18 \mathrm{~F}$-fluorodeoxyglucose positron emission tomography in esophageal cancer. J ClinOncol 22: 3805-3812.

15. Lightdale CJ, Kulkarni KG (2005) Role of endoscopicultrasonography in the staging and follow-up ofvesophageal cancer. J Clin Oncol 23 4483-4489. 
Citation: Haidar M, Bannoura S, Hallal A, Ghanem AA, Dergham MY, et al. (2017) A Case Report of False Positive FDG- PET/CT Mediastinal Lymph Node in Oesophageal Adenocarcinoma Revealed to be an Anthracotic and Anthracosilicotic Spindle Cell Pseudotumor (AASCP). J Nucl Med Radiat Ther 8: 335. doi:10.4172/2155-9619.1000335

Page 4 of 4

16. Bruzzi JF, Truong MT, Macapinlac H (2007) Integrated CT-PET imaging of esophageal cancer: Unexpected and unusual distribution of distant organ metastases. CurrProblDiagnRadiol 36: 21-29.

17. Barber T, Duong CP, Leong T (2012) 18F-FDG PET/CT has a high impact on patient management and provides powerful prognostic stratification in the primary staging of esophageal cancer: Aprospective studywith mature survival data. J Nucl Med 53: 864-871. 